\title{
Numerical comparison on the efficiency of conventional and hybrid buckling-restrained braces for seismic protection of short-to-mid-rise steel buildings
}

\author{
M. Alborzi ${ }^{1} \cdot$ H. Tahghighi ${ }^{1}$ [D $\cdot$ A. Azarbakht ${ }^{2}$
}

Received: 1 May 2019 / Accepted: 30 September 2019 / Published online: 11 October 2019

(C) The Author(s) 2019

\begin{abstract}
Buckling-restrained brace (BRB) is a specific kind of bracing system which has an acceptable energy dissipation behavior in a way that would not be buckled in compression forces. However, considerable residual deformations are noticed in strong ground motions as a result of the low post-yield stiffness of the BRBs. The seismic performance of a modern lateral load resisting system, which is called the hybrid BRB, and its conventional counterpart are assessed and compared in this paper. Multiple plates with different stress-strain behavior are used in the core of this new innovative system, and this is its difference with the existent BRBs. Nonlinear static and incremental dynamic analyses are carried out for three building frames with different structural heights, which use conventional and hybrid BRB systems. To carry out response history analyses, the FEMA P695 far-field earthquake record set was adopted in different hazard levels. The hybrid BRBs are shown to have superior seismic performance in comparison with the conventional systems based on the response modification factor and the damage measures including residual displacements and inter-story drift ratios.
\end{abstract}

Keywords Seismic assessment $\cdot$ Hybrid buckling-restrained brace $\cdot$ Performance factor $\cdot$ Residual displacement $\cdot$ Nonlinear analysis

\section{Introduction}

Steel concentric braced frame (CBF) is frequently applied as a lateral load resisting system, and it is highly effectual (López and Sabelli 2004). The lateral strength and the stiffness are boosted using the steel braces. This happens by inelastic deformation during earthquake ground motions, and an acceptable energy dissipation takes place (Kiggins and Uang 2006). When an earthquake happens, tension and compression loads influence the bracing members alternatively (Ariyaratana and Fahnestock 2011). Past researches indicate that the lateral response of CBFs is dependent on the inelastic behavior of these members (Broderick et al. 2008). Yielding and energy dissipation happen due to the

H. Tahghighi

tahghighi@kashanu.ac.ir

1 Civil Engineering Department, Faculty of Engineering, University of Kashan, Kashan 8731753153, Iran

2 Civil Engineering Department, Faculty of Engineering, Arak University, Arak, Iran post-buckling hysteresis behavior of braces and cyclic loading as well (Miller et al. 2012). Buckling of the braces causes limitation in the energy dissipation capacity in steel braced structures though (Tremblay et al. 2008).

The conventional bracing behavior, in nonlinear range of deformation, has several disadvantages: ductility is not acceptable, hysteresis curves are non-symmetrical in tension and compression, strength is deteriorated, and stiffness is degraded due to buckling under cyclic loading. Therefore, modern CBF systems with stable hysteretic behaviors, considerable ductility, and excellent energy dissipation capacity are desirable, and researchers tried to advance CBF systems (Kumar et al. 2007). Buckling-restrained brace (BRB) is a specific group of concentric bracing system, and it can be yielded under tension as well as compression (Sabelli et al. 2003). The BRB is made up of a steel core and a casing. The casing, which confines buckling of the core, is typically constructed of a mortar filled steel tube. The core and casing are isolated using a de-bounding material or a minimal air gap to ignore the transference of axial force to the casing (Bozorgnia and Bertero 2004). Unlike conventional CBFs, the BRB system has almost symmetrical behavior 
under tension and compression; therefore, energy dissipation capacity is much better, and unbalanced vertical forces are slight. Consequently, lighter beam sections are required compared to CBFs with $\mathrm{V}$ or inverted-V bracing shapes (AISC 2010).

The most crucial problem of the ordinary bucklingrestrained braced frames (BRBFs) is the probable large residual deformations after severe earthquakes, and it has been described in the analytical and empirical study (Jarrett et al. 2015). Large residual lateral deformations in the last strong ground motions have shown that some structures did not face significant damage or partial collapse during the earthquake; nevertheless, they needed to be replaced by a new structure (Qiu and Zhu 2017). Sabelli et al. (2003) did numerical research on BRBF which demonstrated that the residual story drifts are approximately 40 to 60 percent of the highest drifts. Energy dissipation is acceptable in BRBFs, but the renovation cost could be high for a significant earthquake. This is because of the low post-yield stiffness and not having a re-centering mechanism. Reducing the residual deformations in BRBFs is the first purpose of improvements to BRBs. Having a higher performance standard than the life safety in structures is the other purpose that BRBs improvement focused on. Applying the backup moment frame system in a dual-frame is another solution to alleviate the permanent deformation as well as to reach higher performance levels in the BRBFs (Kiggins and Uang 2006). They demonstrated that the residual drifts are lessened by more than $50 \%$ when a dual system is applied. Using the self-centering energy dissipative bracing system is another way of removing the residual deformation of BRBFs (Miller et al. 2012; Tremblay et al. 2008; Kammula et al. 2014). Providing an elastic remaining element is the concept of this system. Obviously, the fuse element yields and consequently dissipates energy in this system. Increasing the cost of buildings is the main disadvantage of self-centering systems. Hoveidae et al. (2015) studied a new type of BRB, in which a shorter core component was serially connected to a semi-rigid non-yielding member. They showed that the short-core BRBs can considerably reduce the residual drifts of BRBFs. Dong et al. (2017) proposed an innovative selfcentering BRB system for mitigating the seismic response of bridge structures with double column piers. The research results indicated that the proposed system can reduce residual drifts and exhibited moderate energy dissipation capacity. A hybrid BRB (HBRB) is another innovative idea related to BRBs which uses a multi-core BRB using various steel grades. Atlayan and Charney (2014) showed that the hybrid BRBF experiences significantly smaller residual drifts with the lowest modification to the regular BRBFs.

In the HBRB system, various steel materials are combined in the brace core; therefore the brace behavior is adjusted by managing the order of the yielding and post-yielding behaviors. The HBRB core is made up of the conventional carbon steel (A36), the low yield point (LYP) steel, and the high-performance steel (HPS). The HBRB system shows better behavior at low to mid-intensity hazard levels and this is due to LYP yielding point which results in limited inelastic energy-dissipation. Moreover, the negative slope is reduced in end regions of capacity curves, because LYP has a high strain hardening. Totally, LYP has better performance in energy dissipation. This point can lead to a better seismic response. LYP100 is low-carbon steel with the average yield strength of about $100 \mathrm{MPa}$ which is used as the LYP steel in the above study (Saeki et al. 1998). The modulus of elasticity is the same in comparison with the conventional A36 carbon steel, but the rupture strain in the LYP100 is 1.5-2 times comparing to the mild steel (Nakashima et al. 1994). The LYP100 can be found in Japanese markets now, and its price is almost twice over in comparison with the conventional A36 steel (Nippon Steel 2009). The HPS materials are available in two grades, including HPS70W and HPS100W (Günther and Raoul 2005). The combination of HPS and low strength steel in the core of BRBs has been reported to provide strength and increase the efficiency of the frame by reducing the possibility of dynamic instability during strong ground motions (Sugisawa et al. 1995; Chen et al. 2001). Therefore, controlling the yielding behavior in the chosen members of the structure is the principal goal of the system. Additionally, it can be said that the hybrid frame is yielded sooner than the conventional frame and the negative post-yield slope is expected in higher drift levels (Atlayan and Charney 2014). Figure 1 shows the layout of the multi-material core HBRB.

According to all the above findings, this research aims to gain an understanding of whether the use of the innovative hybrid BRBs can perform better than the conventional counterpart in steel buildings with various heights. The characteristics of the seismic sequences were examined considering performance factors, inter-story drift ratio (IDR), and residual displacement. To do this, an extensive parametric study, with different approaches of analysis, is performed for assessing and comparing the seismic response of lowto-mid-rise conventional and hybrid steel BRBF buildings subjected to lateral static pushover loadings and earthquake ground motion records of different hazard levels. The numerical outcomes show that the new hybrid systems improve the seismic behavior of the conventional BRBFs, which is significantly important to the performance-based design of steel braced structures.

\section{Building description}

The performance of conventional and hybrid BRBs has been investigated utilizing 5-, 8- and 12-story braced frames. The type of brace configuration in BRBFs is diagonal. The 
Fig. 1 Multi-material core HBRB configuration

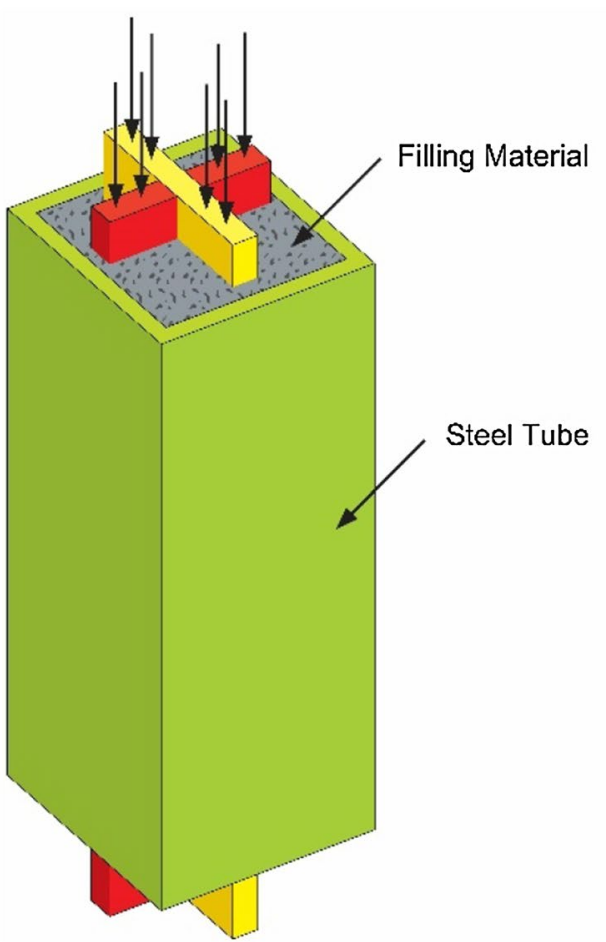

building models have a floor plan of $45.7 \times 45.7 \mathrm{~m}$. Figure 2 indicates the frames elevation and the typical floor plan. The building plan is the same as the one used in the book by Bruneau et al. (2011). The example models represent a large number of short to moderate office structures located in relatively high-risk earthquake-prone regions like Iran. As will be explained in "Numerical analysis", the numerical analyses are carried out on one of the boundary three-bay braced frames as seen in Fig. 2b. The story heights of the models were considered as 5.5 and $4 \mathrm{~m}$, respectively, in the case of the first and the other floors. The requirements of the Iranian national building codes (MHUD 2013a, b, the Iranian code of practice for the seismic-resistant design of buildings known as Standard no. 2800 (BHRC 2014), and seismic provision of FEMA P695 (2009) have been considered in the design of the buildings. Gravity loadings were

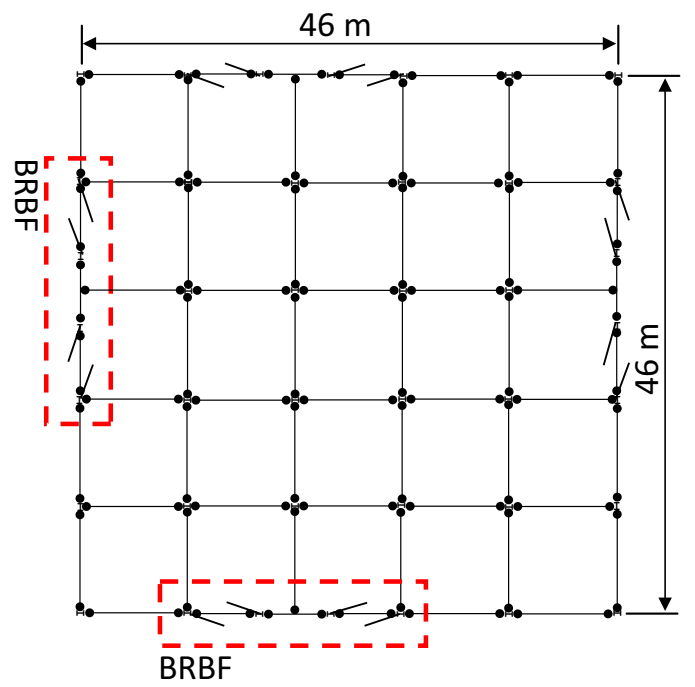

(a)

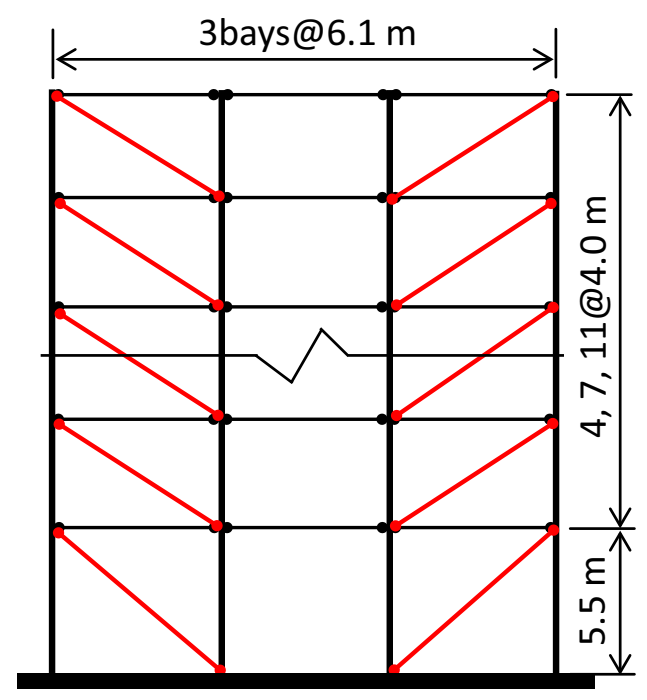

(b)

Fig. 2 Case study BRBF models: a typical floor plan and $\mathbf{b}$ typical frame elevation 
considered as $6 \mathrm{kN} / \mathrm{m}^{2}$ for dead loads and $2.5 \mathrm{kN} / \mathrm{m}^{2}$ for live loads. The important factor of $I=1$, seismic zone factor of $A=0.30$, soil type III and the ultimate response modification factor of $R=7.0$ have been considered within the frames design procedure. St-37 steel type has been applied to the structural beam and column members in this study.

The details of material characteristics and compounds of various hybrid BRB layouts that were applied to the models are summarized in Tables 1 and 2. To make a distinct comparison between conventional and hybrid frames, the steel core areas are assigned in a way that total stiffness of the BRBs will be the same. In this case, the standard and hybrid BRBs will absorb the same level of seismic force. Also, since the beam and column design in BRBFs depends on the adjusted brace strengths, the total strength of the brace was kept unchanged so that the same beam and column sections could be used in conventional and hybrid BRBF buildings. In Table 2, the core area, total stiffness, and total strength are shown as ratios. The steel core areas in BRBFs are specified in a way that total stiffness and strength of conventional and hybrid BRBs will be the same. Structural A36 steel with $290 \mathrm{MPa}$ yield strength is applied to the conventional BRB, but LYP100, HPS100W, and HPS70W have been added to core materials in hybrid BRBs. The braces have been considered to withstand the entire lateral load, and all beam-column joints are pinned and not moment resisting. Beams, columns, and connections in the frame have to stay elastic through the required strength of the BRB. Therefore, a modified brace strength is assumed. Allocated structural members for the braced structures (Fig. 2) are mentioned in Table 3.

The foundations and the superstructures have been commonly designed as two separated systems, and the superstructures were restricted at the bottom. As a result, the assessed seismic evaluation of the buildings only relies on the superstructures. This approach is useful and straightforward, but the flexibility of the foundation has to be considered; otherwise, the dynamic characteristics

Table 1 Material properties

\begin{tabular}{lllll}
\hline & A36 & LYP100 & HPS70W & HPS100W \\
\hline$F_{y}(\mathrm{MPa})$ & 290 & 107 & 503 & 745 \\
$E(\mathrm{Gpa})$ & 200 & 186 & 200 & 200 \\
\hline
\end{tabular}

Table 3 Details of steel BRBF members

\begin{tabular}{|c|c|c|c|c|}
\hline & Story level & $\begin{array}{l}\text { Brace } \\
\text { area } \\
\left(\mathrm{cm}^{2}\right)\end{array}$ & Beam section & $\begin{array}{l}\text { Column } \\
\text { section }\end{array}$ \\
\hline \multirow[t]{6}{*}{ 5-Story model } & Roof & - & W460×74 & - \\
\hline & 5 & 19.4 & $\mathrm{~W} 460 \times 89$ & $\mathrm{~W} 360 \times 110$ \\
\hline & 4 & 29.0 & W530×109 & $\mathrm{W} 360 \times 110$ \\
\hline & 3 & 38.7 & W530×109 & $\mathrm{W} 360 \times 110$ \\
\hline & 2 & 45.2 & W530× 123 & $\mathrm{~W} 360 \times 216$ \\
\hline & Ground & 51.6 & - & $\mathrm{W} 360 \times 216$ \\
\hline \multirow[t]{9}{*}{ 8-Story model } & Roof & - & W530× 123 & - \\
\hline & 8 & 29 & W530×123 & $\mathrm{W} 360 \times 110$ \\
\hline & 7 & 29 & W530× 123 & $\mathrm{~W} 360 \times 110$ \\
\hline & 6 & 45.2 & W530× 123 & $\mathrm{~W} 360 \times 216$ \\
\hline & 5 & 45.2 & W530×123 & $\mathrm{W} 360 \times 216$ \\
\hline & 4 & 58.1 & W530×123 & $\mathrm{W} 360 \times 216$ \\
\hline & 3 & 58.1 & W530×123 & $\mathrm{W} 360 \times 347$ \\
\hline & 2 & 71 & W530×123 & $\mathrm{W} 360 \times 347$ \\
\hline & Ground & 71 & - & $\mathrm{W} 360 \times 347$ \\
\hline \multirow{13}{*}{$\begin{array}{c}\text { 12-Story } \\
\text { model }\end{array}$} & Roof & - & W530×123 & - \\
\hline & 12 & 45.2 & W530× 123 & $\mathrm{~W} 360 \times 347$ \\
\hline & 11 & 45.2 & W530×123 & $\mathrm{W} 360 \times 347$ \\
\hline & 10 & 45.2 & W530× 123 & $\mathrm{~W} 360 \times 347$ \\
\hline & 9 & 45.2 & W530×123 & $\mathrm{W} 360 \times 347$ \\
\hline & 8 & 83.9 & W530×123 & $\mathrm{W} 360 \times 509$ \\
\hline & 7 & 83.9 & W530×123 & W360×509 \\
\hline & 6 & 83.9 & W530× 123 & $\mathrm{~W} 360 \times 509$ \\
\hline & 5 & 83.9 & W530×123 & $\mathrm{W} 360 \times 509$ \\
\hline & 4 & 96.8 & W530× 123 & $\mathrm{~W} 460 \times 463$ \\
\hline & 3 & 96.8 & W530× 123 & $\mathrm{~W} 460 \times 463$ \\
\hline & 2 & 96.8 & W530× 123 & $\mathrm{~W} 460 \times 463$ \\
\hline & Ground & 96.8 & - & $\mathrm{W} 460 \times 463$ \\
\hline
\end{tabular}

and seismic performance of structures may be considerably diverse from those of the real demands (Tahghighi and Rabiee 2017; Wolf 1985). Therefore, investigating the effect of foundation flexibility on the seismic behavior of steel braced frame structures is required as a further study.
Table 2 Hybrid BRB combinations

\begin{tabular}{llllll}
\hline & Material & Conventional BRB & HBRB-1 & HBRB-2 & HBRB-3 \\
\hline Area ratios & A36 & 1.00 & 0.167 & - & - \\
& LYP100 & - & 0.493 & 0.614 & 0.776 \\
& HPS70 W & - & 0.375 & 0.446 & - \\
& HPS100 W & - & - & - & 0.278 \\
Total stiffness $(\times \mathrm{A} / \mathrm{L})$ & & 200,000 & 200,098 & 203,384 & 199,936 \\
Total strength $(\times \mathrm{A})$ & & 290.0 & 289.8 & 290.0 & 290.1 \\
\hline
\end{tabular}




\section{Earthquake ground motions}

The structural response can be different in a response-history analysis. Estimation of the structural seismic performance needs to be more precise. Therefore, the selection of earthquake ground motions is so important. By employing twenty-two far-field records suggested by the Applied Technology Council (FEMA P695 2009), the variety has been reduced and the randomness of the ground motions is kept in this paper. The FEMA P695 set has been applied for seismic performance assessment in many kinds of researches, for instance, ATC 76 (NIST 2010) and ATC 84 (NIST 2012). The considered set of ground motions is neither structure specific nor site specific and has ground motion records from the PEER-NGA database (PEER 2015). The event moment magnitude is from 6.5 to 7.6. All motions have been recorded on medium soil site with the lowest distance to the fault rupture of more than $10 \mathrm{~km}$ except one with $7.1 \mathrm{~km}$ to the fault plane, having low to medium PGA from $0.21 \mathrm{~g}$ to $0.82 \mathrm{~g}$, and the average value of $0.43 \mathrm{~g}$.

Properties of the selected ground motions are shown in Table 4. A more in-depth analysis and extended information regarding this dataset can be seen in Appendix A in
FEMA P695 (2009). The ground motion records have been independently scaled based on the processes described in Standard no. 2800 at earthquake hazards of 50\%, $10 \%$ and 2\% in 50 years (MHUD 2013a). The ground motion acceleration response spectra for $10 \%$ in 50 years hazard are shown in Fig. 3. It should be said that the earthquake ground motions which are near to a ruptured fault and those further away from the source are completely different. Near-fault motions are considerably affected by the forward rupture directivity and fling step (Tahghighi 2012). Thus, the detailed seismic assessment of hybrid BRBF systems against conventional braced frames by taking the near-fault pulse-like ground motion effects into account can be an interesting issue for further future researches. According to the recent findings, the seismic performance of mid-rise concentrically braced frames designed based on Standard no. 2800, deteriorated under near-field ground motions (Systani et al. 2016).

\section{Numerical analysis}

The computational model of the perimeter braced frames, as shown in Fig. 2b, was developed using the OpenSees finite element platform (OpenSees 2016). Beams and columns
Table 4 Characteristics of considered FEMA P695 farfield earthquake records (PEER 2015)

\begin{tabular}{lllllll}
\hline No. & Earthquake & Year & Station & $M_{w}$ & $d(\mathrm{~km})$ & PGA $_{\max }(\mathrm{g})$ \\
\hline 1 & Northridge, USA & 1994 & Beverly Hills-Mulhol & 6.7 & 17.2 & 0.52 \\
2 & Northridge, USA & 1994 & Canyon Country-WLC & 6.7 & 12.4 & 0.48 \\
3 & Duzce, Turkey & 1999 & Bolu & 7.1 & 12 & 0.82 \\
4 & Hector Mine, USA & 1999 & Hector & 7.1 & 11.7 & 0.34 \\
5 & Imperial Valley, USA & 1979 & Delta & 6.5 & 22 & 0.35 \\
6 & Imperial Valley, USA & 1979 & El Centro Array \#11 & 6.5 & 12.5 & 0.38 \\
7 & Kobe, Japan & 1995 & Nishi-Akashi & 6.9 & 7.1 & 0.51 \\
8 & Kobe, Japan & 1995 & Shin-Osaka & 6.9 & 19.2 & 0.24 \\
9 & Kocaeli, Turkey & 1999 & Duzce & 7.5 & 15.4 & 0.36 \\
10 & Kocaeli, Turkey & 1999 & Arcelik & 7.5 & 13.5 & 0.22 \\
11 & Landers, USA & 1992 & Yermo Fire Station & 7.3 & 23.6 & 0.24 \\
12 & Landers, USA & 1992 & Coolwater & 7.3 & 19.7 & 0.42 \\
13 & Loma Prieta, USA & 1989 & Capitola & 6.9 & 15.2 & 0.53 \\
14 & Loma Prieta, USA & 1989 & Gilroy Array\#3 & 6.9 & 12.8 & 0.56 \\
15 & Manjil, Iran & 1990 & Abbar & 7.4 & 12.6 & 0.51 \\
16 & Superstition Hills, USA & 1987 & El Centro Imp. Co. & 6.5 & 18.2 & 0.36 \\
17 & Superstition Hills, USA & 1987 & Poe Road (temp) & 6.5 & 11.2 & 0.45 \\
18 & Cape Mendocino, USA & 1992 & Rio Dell Overpass & 7 & 14.3 & 0.55 \\
19 & Chi-Chi, Taiwan & 1999 & CHY101 & 7.6 & 10 & 0.44 \\
20 & Chi-Chi, Taiwan & 1999 & TCU045 & 7.6 & 26 & 0.51 \\
21 & San Fernando, USA & 1971 & LA-Hollywood Stor & 6.6 & 22.8 & 0.21 \\
22 & Friuli, Italy & 1976 & Tolmezzo & 6.5 & 15.8 & 0.35 \\
\hline
\end{tabular}

$P G A_{\max }$ maximum value of peak ground acceleration of the two horizontal components, $d$ closest distance to the fault plane, $M_{w}$ moment magnitude 
Fig. 3 The single-record and the average elastic response spectra (5\% damping) of the selected ground motions

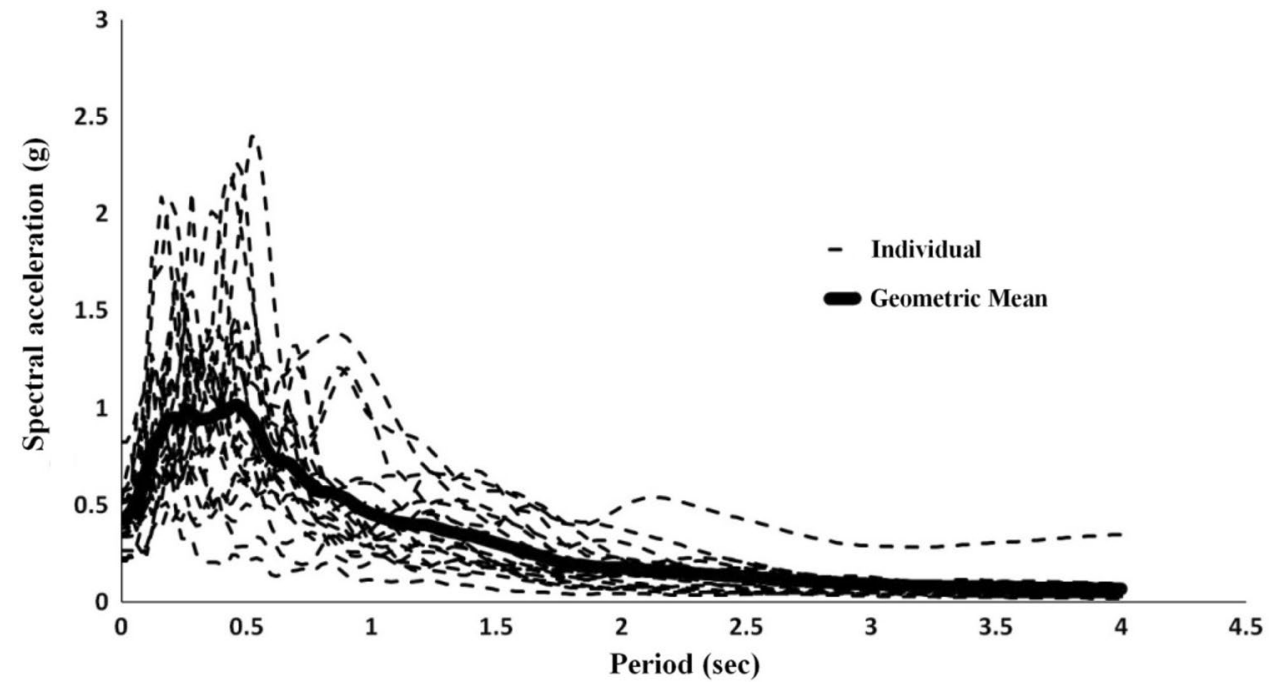

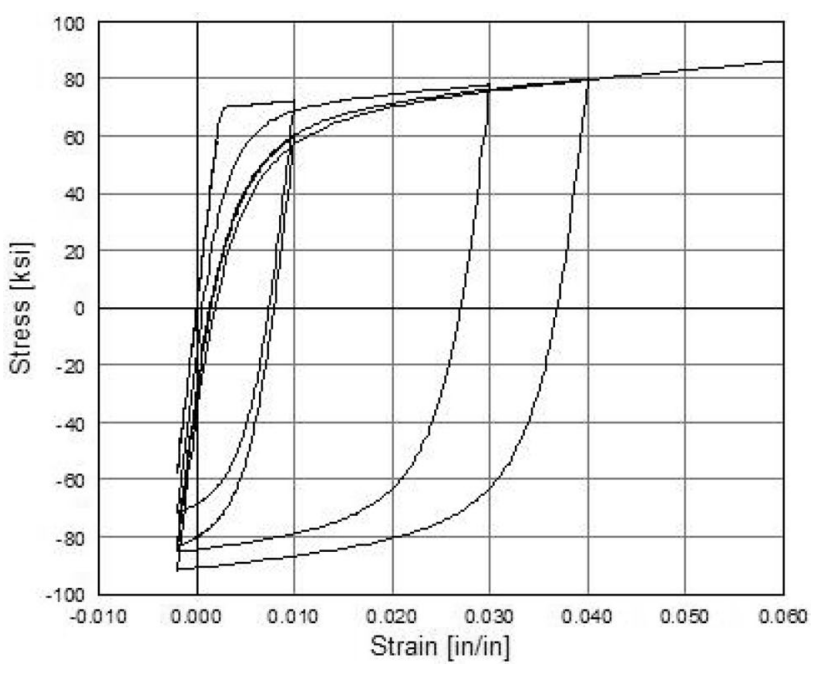

Fig. 4 Stress-strain relationship of the Steel02 material (OpenSees 2016)

have been modeled by nonlinear beam-column elements with fiber sections and columns were constrained at the base. Second-order effects have been modeled by a leaning column. Beam-column connections and brace to frame connections are made of rigid offsets to model the gusset plates. The Giuffre-Menegotto-Pinto steel with isotropic strain hardening, known as Steel02 in OpenSees, is allocated to fibers as material (Fig. 4). This material model can account for accumulated plastic deformation at each point of load reversal. Accordingly, each hysteretic loop follows the previous loading path for a new reloading curve, while deformations accumulate. A co-rotational truss element with yielding steel core is used to model the BRBs. The equivalent elastic modulus was applied to model the yielding and the non-yielding parts of the brace's length because a single truss element was applied across the whole brace's length. The effect of the gravity framing system was neglected in the models. It was presumed that different steel cores are joined in parallel; therefore, two or three brace elements were assigned on top of each other in the numerical models. To clarify the comparative effect of hybridity on the seismic performance of BRBFs, numerous nonlinear static and dynamic analyses have been performed for the different considered modeling approaches.

\section{Nonlinear static analysis}

Nonlinear static analysis, by using pushover procedures, has been widely carried out to foresee the inelastic force-deformation behavior of a given building. Broadly, the efficiency of nonlinear static pushover analysis for predicting the structural performance needs to be discussed. Nevertheless, understanding the anticipated behavior of structures is possible through this simple method (Vamvatsikos and Fragiadakis 2009). Lateral loads were applied to the structure models according to the suggested patterns of FEMA 356 guidelines (FEMA 356 2000), and then pushover analysis was carried out. The base shear versus roof displacement diversities for different bracing conditions and Frames with various stories was determined through a displacement-controlled algorithm. Figure 5 shows the comparison of capacity curves and in fact, compares base shear against roof drift ratio for the hybrid-3 five-story frame with the corresponding results of Ref. (Atlayan and Charney 2014). It is clear that simulated capacity curves are similar to some extent. Thus, quite accurate building response analysis can be expected by applying the hybrid BRB model in this research.

Famous seismic design parameters including the ductility $\left(\mu_{T}\right)$, overstrength $(\Omega)$ and response modification $(R)$ factors are computed to make the comparison. Two parameters, $\mu_{T}$ 


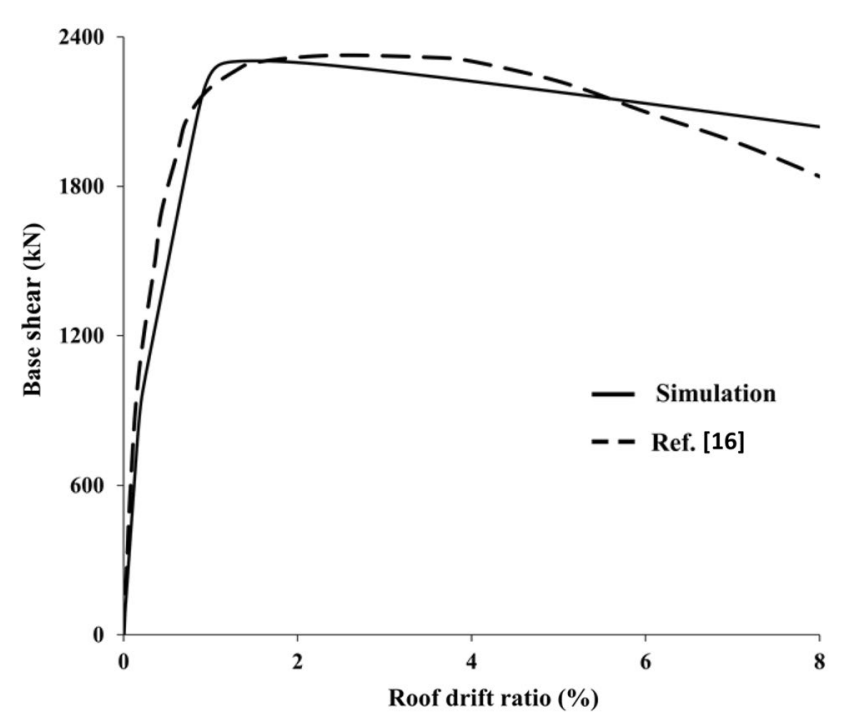

Fig. 5 Comparison of capacity curves for the 5-story HBRB-3 frame

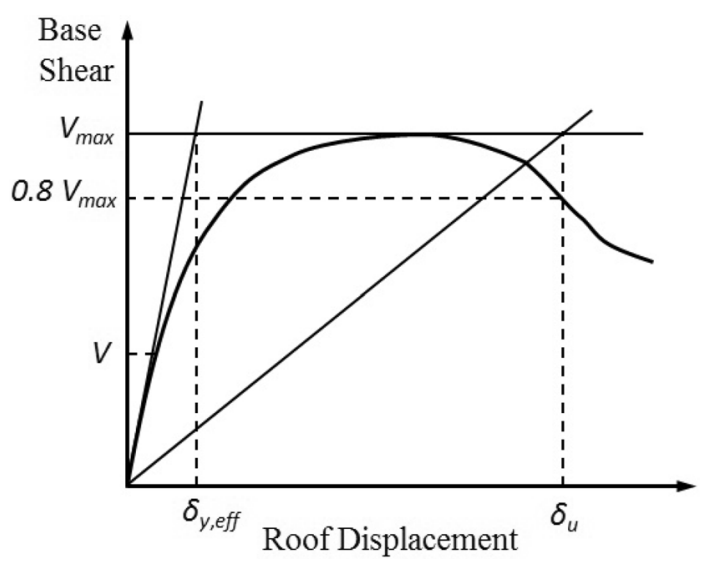

Fig. 6 Idealized nonlinear static pushover curve proposed in FEMA P695 (2009)

and $\Omega$, were determined according to FEMA P695 and the bilinear ideal pushover curves were formed. Afterward, the $R$ factor was calculated. The pushover curves are characterized by applying the ideal bilinear curve based on FEMA P695 guidelines which are shown in Fig. 6. The effective yield roof drift displacement and the maximum base shear resistance are determined by $\delta_{y, \text { eff }}$ and $V_{\max } \cdot \mu_{T}$ and $\Omega$ were calculated by the means of equations $\mu_{T}=\frac{\delta_{u}}{\delta_{\text {y,eff }}}$ and $\Omega=\frac{V \max }{V}$, where $\delta_{u}$ and $V$ show the final roof displacement and design base shear, respectively. When $\Omega$ and $\mu_{T}$ are available, the $R$ factor can be calculated based on Eqs. (1) and (2), where $V_{E}$ is the elastic seismic force demand. The global nonlinear response of a building can be measured by $R_{\mu}$ due to the ductility of the structure (Newmark and Hall $1982)$ and $R_{R}$ is the reduction coefficient due to redundancy, which was set equal to one for regular and hybrid BRBF models.

$R_{\mu}= \begin{cases}R_{\mu}=1.0 & T \leq 0.05 \mathrm{sec} \\ R_{\mu}=\sqrt{2 \mu_{T}-1} & 0.12 \mathrm{sec} \leq T \leq 0.5 \mathrm{sec}, \\ R_{\mu}=\mu_{T} & T \geq 1.0 \mathrm{sec}\end{cases}$

$R=\frac{V_{E}}{V_{s}}=R_{R} R_{\mu} \Omega$

\section{Incremental dynamic analysis}

The seismic behavior of structures needed to be assessed more precisely; therefore, an increasing analysis method called the incremental dynamic analysis (IDA) was promoted. IDA is a parametric analysis approach. A set of nonlinear analyses have to be constructed under multiple scaled earthquake records. The ground motion intensities are chosen in a way that can take the entire range from elasticity to global dynamic instability (Vamvatsikos and Cornell 2002).

Two fundamental quantities named Damage Measure (DM) and Intensity Measure (IM) are used for presenting IDA curves. DM is an observable quantity that is obtained from the outcomes of the nonlinear dynamic analysis. It is noteworthy that the suitable quantity for DM is chosen considering the type of problem or the intended structure. In this research, DM is described concerning residual roof displacement and maximum IDR which are known to connect well to structural damage during the seismic performance-based assessment of multi-story buildings (Kiggins and Uang 2006; Ruiz-Garcia and Miranda 2010; Atlayan 2013).

For the structural systems, the intensity measure (IM) is also defined using the relatively efficient $5 \%$ damped firstmode spectral acceleration, $S_{a}\left(T_{1}, 5 \%\right)$ (In units of g). $S_{a}\left(T_{1}\right.$, $5 \%$ ) seems desirable to the structure-independent IM, i.e., $P G A$, producing lower dispersion in the IDA results (Vamvatsikos and Cornell 2005a, b). It is necessary to note that IDA can be significantly reliant on the selected record, so we need a suite of records to have acceptable precision in estimating seismic demands, $S_{a}\left(T_{1}, 5 \%\right.$ ) (Shome and Cornell 1999). Accordingly, IDA was carried out by using the 22 progressively scaled records, listed in Table 4 . Each selected acceleration record is scaled in from linear range (initial elastic) to nonlinear range with IM steps of $0.01 \mathrm{~g}$ for increasing the efficiency of the outcomes in incremental dynamic analyses. Therefore, the whole range of models' behavior is covered from the elastic state until yield and collapse points. Finally, by inserting the taken pairs of $S_{a}\left(T_{1}\right.$, $5 \%$ ) and DM parameters, we get continuous IDA curves for each record, and the corresponding summarized median IDA 
curves for each conventional and hybrid multi-story BRBF buildings.

\section{Results and discussion}

The purpose of this section is to investigate and compare the performance of hybrid and regular BRBF concerning seismic behavior factors, IDRs, and residual displacements. The OpenSees platform has been adopted to carry out nonlinear static pushover, nonlinear response history, and incremental dynamic analyses. The results of different cases are extracted, compared and discussed in the next sections.

\section{Seismic performance factors}

Following the procedures outlined in "Nonlinear static analysis", Fig. 7 shows the base shear versus roof drift ratio for all the studied frames, i.e., the regular and three hybrid BRBFs. As shown in Fig. 7, the hybridity effect increases the post-yield stiffness of the frames as a result of high strain hardening effect in the LYP100 material, particularly in the case of the HBRB-3 model. However, the elastic stiffness and the total base shear capacity were not influenced in this particular way. It should be noticed that HPS70W and HPS 100 W materials lead to hybrid BRBs with LYP100 have an equal total capacity to the conventional BRBF. As explained previously, the hybrid BRBFs counteracts the negative post-yield stiffness that happens as a result of $P-\Delta$ effects. Hence, the application of the hybrid system is beneficial in mid-to-high-rise buildings where $P-\Delta$ effects are more critical due to the high gravity loads. It can be seen in Fig. 7 that hybrid frames yield sooner than typical frames. The early yielding and the procrastination in negative postyield stiffness drift ratio are becoming clear as frames are becoming more hybrid (from HBRB-1 to HBRB-3). The roof displacement-base shear taken from pushover analysis for 5-, 8- and 12-story frames is shown in Fig. 8. It is visible that the global stiffness of the system diminishes as the height of the building rises.

The seismic performance factors were first presented in the ATC 3-06 report (ATC 3-06 1978). These factors were named response modification factors (or coefficients) in the past. Based on the estimated ultimate roof displacement, $\delta_{u}$, Table 5 provides the distribution of period-based ductility, $\mu_{T}$, for each given frame buildings. Next, by having $V_{\max }$ and $V$, the over-strength coefficient was computed for all models. It is observed that transformations in $\Omega$, as a result of hybridity effects, are not that much important. In other words, the over-strength factors are not influenced by the sort of brace. According to eigenvalue analyses, the fundamental periods of 5-, 8- and 12-story frames are, respectively, $1.37 \mathrm{~s}, 1.99 \mathrm{~s}$, and $2.89 \mathrm{~s}$. Hence, using the Newmark and Hall relationships
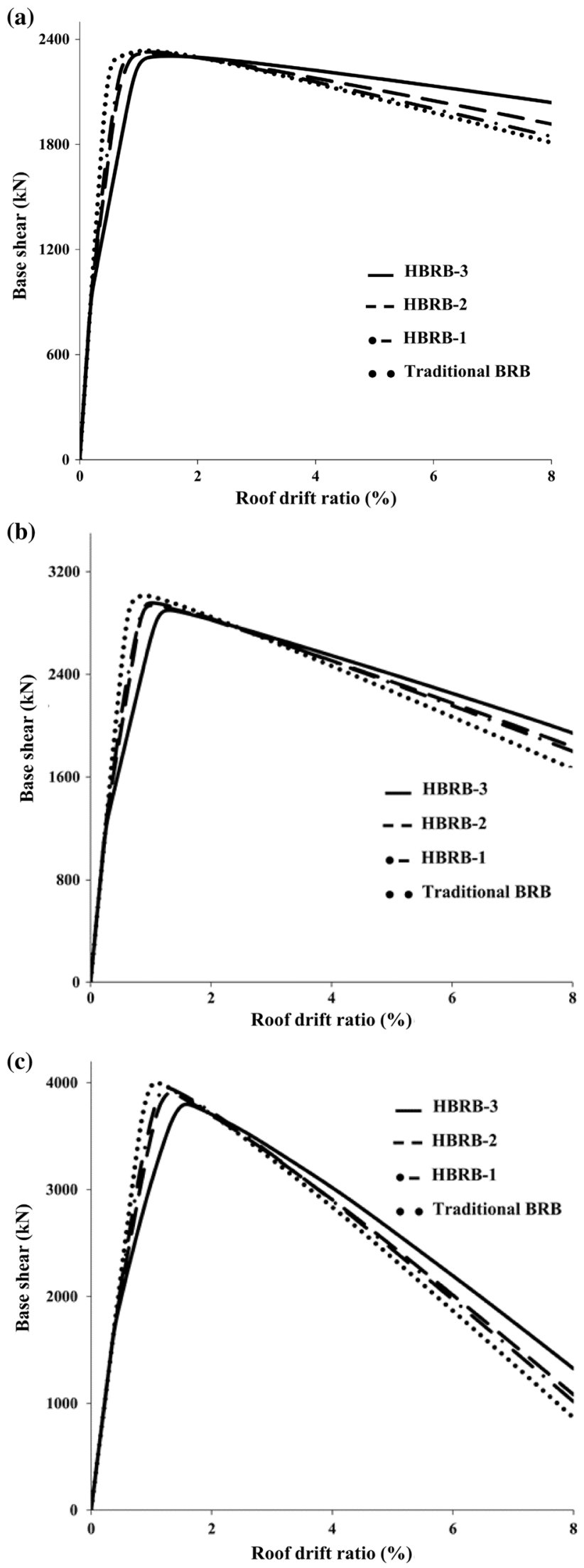

Fig. 7 Base shear vs. roof drift ratio, conventional and hybrid BRBFs: a 5-story frame, b 8-story frame and c 12-story frame 
Fig. 8 Base shear vs. roof displacement: a conventional BRB models, b HBRB-1 models, c HBRB-2 models and d HBRB-3 models

[i.e., Equation (1)], the ductility and over-strength coefficients were employed to determine $R$ factor according to Eq. (2). As seen in Table 5, the average performance factors of HBRB-3, HBRB-2, HBRB-1, and the conventional BRB models reach for $R_{\mu} 8.34,6.86,6.63$ and 6.42, respectively, and for $R 12.9,10.5,10.2$ and 9.8, respectively. It is recognized that $R_{\mu}$ and $R$ showed a significant decrease in frames while the number of stories rises. The obtained results indicate that the use of hybrid BRB could lead to a noticeable increase in the response modification factor, particularly in the case of the HBRB-3 model. A further comparison of the seismic behavior of steel frames constrained with hybrid core buckling-restrained braces is discussed by Alborzi Verki and Tahghighi (2019).

In former studies, the seismic response modification factor for the conventional BRBFs has been suggested as 8.35 by Asgarian and Shokrgozar (2009). Another study revealed the value of $R$ equal to 12.2 on average for BRBFs with various stories (Mahmoudi and Zaree 2010). Further, recent code-compliant seismic designs such as Standard No. 2800 (BHRC 2014); ASCE 7 (2010); and AISC (2010) recommend a constant value of response modification coefficient for conventional BRBF systems. According to these provisions, the $\mathrm{R}$ factor varies between 7 and 8 . It is worth mentioning that the assessed response modification factors are various in this paper regarding both the brace type and the building height. Consequently, the BRB provisions included in seismic standards need to be modified and/or updated based on continuing research to be able to achieve a safer and more economic structural design.

\section{Response history analysis results}

Subsequent to the pushover analysis, the nonlinear dynamic response history analyses are performed applying the records in Table 4 . They capture both geometrical $(P-\Delta$ effects) and material nonlinearities. The transient analysis with the solution parameters of $\gamma=0.5$ and $\beta=0.25$ is carried out by applying the Newmark linear acceleration approach (Chopra 2012). The critical damping ratio is set to $2 \%$ at the first and third modes as it is commonly regarded in steel frame structures literature. The nonlinear equilibrium equations are solved by applying the modified Newton-Raphson algorithm with a convergence tolerance of $1.0 \mathrm{E}-8$ more than a maximum of 1000 repetitions. The stiffness matrixes are altered by limiting the restricted degrees of freedom in the transformation approach. This method is used in the analysis as a constraint handler. The size of the system for multi-point constraints is reduced employing this approach (OpenSees 2016).
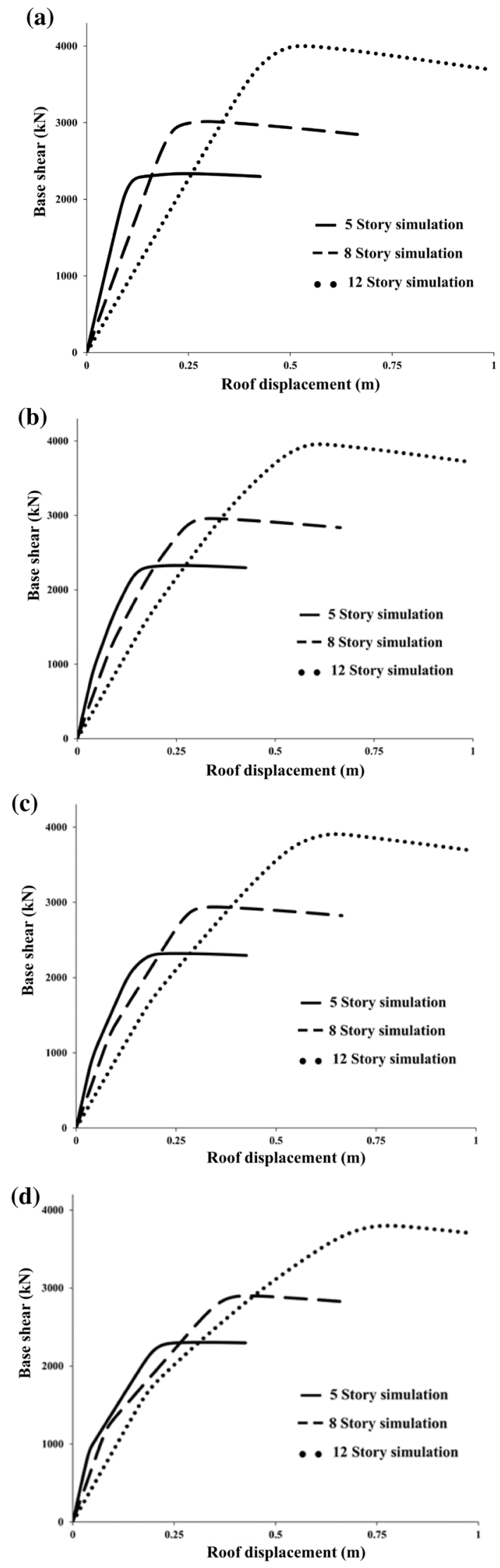
Table 5 Response modification factor of hybrid BRBFs against conventional ones

\begin{tabular}{llllllrrr}
\hline Building model & $V_{\max }(\mathrm{kN})$ & $V(\mathrm{kN})$ & $\delta_{u}(\mathrm{~m})$ & $\delta_{y, \text { eff }}(\mathrm{m})$ & $\Omega$ & $\mu_{T}$ & $R_{\mu}$ & $R$ \\
\hline HBRB-3 & & & & & & & & \\
$\quad 5$ story & 2293 & 1435 & 1.46 & 0.102 & 1.6 & 14.3 & 14.3 & 22.9 \\
8 story & 2988 & 1992 & 1.46 & 0.207 & 1.5 & 7.1 & 7.1 & 10.6 \\
12 story & 3960 & 2688 & 1.61 & 0.442 & 1.47 & 3.6 & 3.6 & 5.4 \\
HBRB-2 & & & & & & & & \\
5 story & 2273 & 1435 & 1.13 & 0.101 & 1.58 & 11.2 & 11.2 & 17.7 \\
8 story & 2975 & 1977 & 1.24 & 0.207 & 1.5 & 6.0 & 6.0 & 9.0 \\
12 story & 3949 & 2830 & 1.49 & 0.441 & 1.4 & 3.4 & 3.4 & 4.7 \\
HBRB-1 & & & & & & & & \\
5 story & 2269 & 1435 & 1.08 & 0.101 & 1.58 & 10.7 & 10.7 & 16.9 \\
8 story & 2972 & 2014 & 1.21 & 0.206 & 1.48 & 5.9 & 5.9 & 8.7 \\
12 story & 3947 & 2697 & 1.47 & 0.441 & 1.46 & 3.3 & 3.3 & 4.9 \\
Conventional BRB & & & & & & & & \\
$\quad 5$ story & 2265 & 1435 & 1.04 & 0.101 & 1.58 & 10.3 & 10.3 & 16.2 \\
$\quad$ story & 2970 & 2003 & 1.18 & 0.206 & 1.48 & 5.7 & 5.7 & 8.5 \\
12 story & 3944 & 2712 & 1.44 & 0.441 & 1.45 & 3.3 & 3.3 & 4.8 \\
\hline
\end{tabular}

Some representative response history results have been selected to study the general trend of hybridity effects and can be seen in Figs. 9 and 10. The maximum IDR and residual roof displacement are chosen as the primary response parameters to estimate the structural seismic vulnerability. The next parts argue about the influences of hybrid BRB and earthquake intensity on the inelastic seismic response of steel frames and their performance levels. To reach a systematic criterion for analysis, the median responses for every hazard level were assessed and given.

\section{Inter-story drift ratio}

The highest relative displacement between two consecutive stories divided by the height of that story is called the story drift ratio and is the most commonly used damage parameter. Applying hybrid frames improves the median performance regarding the highest IDR, and it is shown in Fig. 9. Based on the nonlinear dynamic response history analyses, the hybrid BRBs are not useful to reduce the IDR of 5- and 8-story frames when compared to the conventional
Fig. 9 The median performance improvements for maximum inter-story drift ratio of the 12-story frame for the three earthquake hazard levels

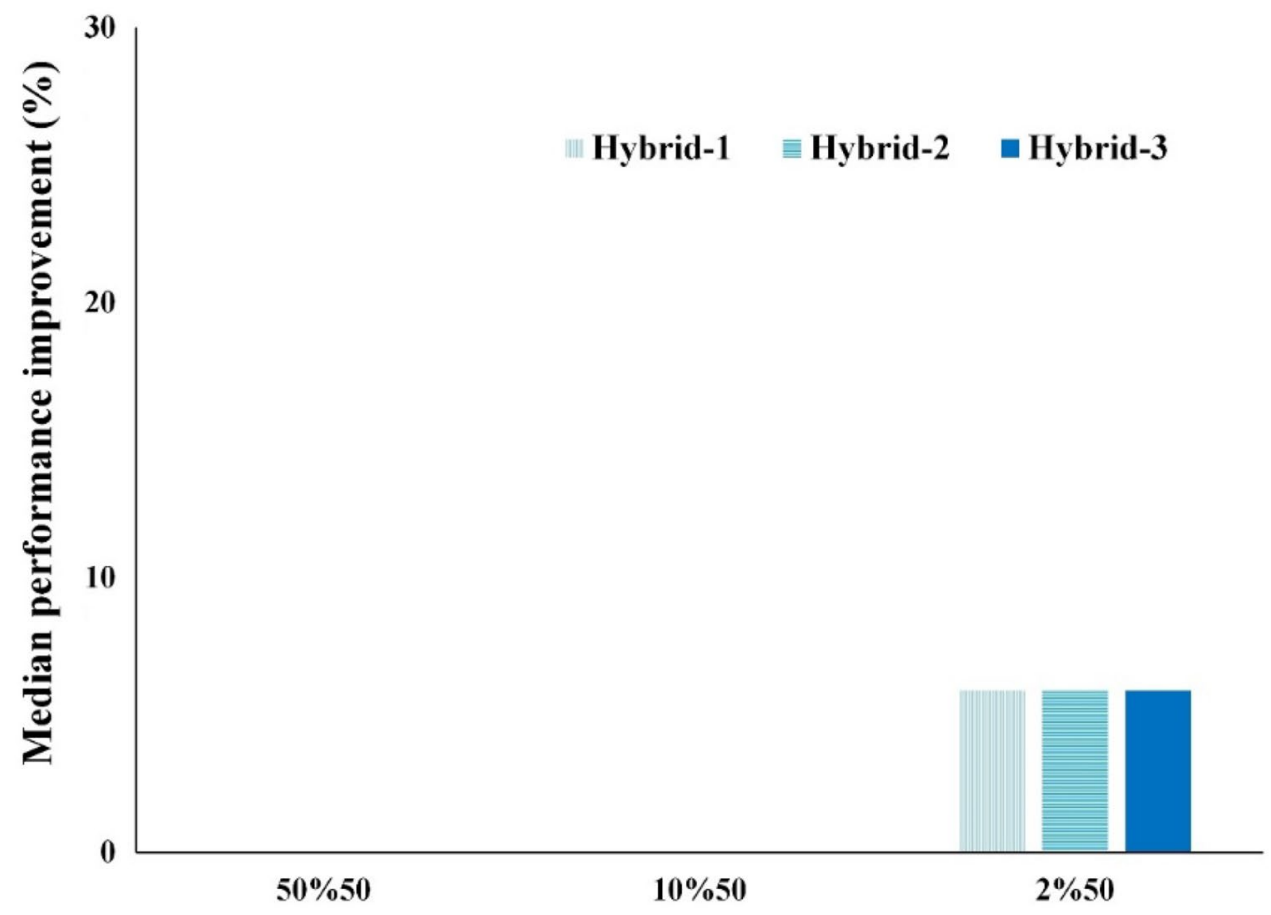


Fig. 10 The median performance improvements for residual roof displacement for the three earthquake hazard levels: a 5-story frame, b 8-story frame and c 12-story frame (a)

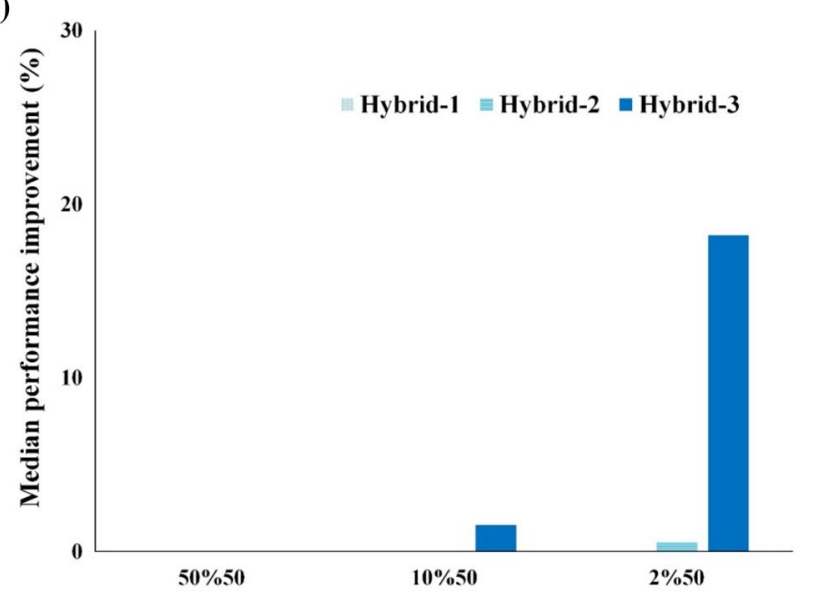

(b)
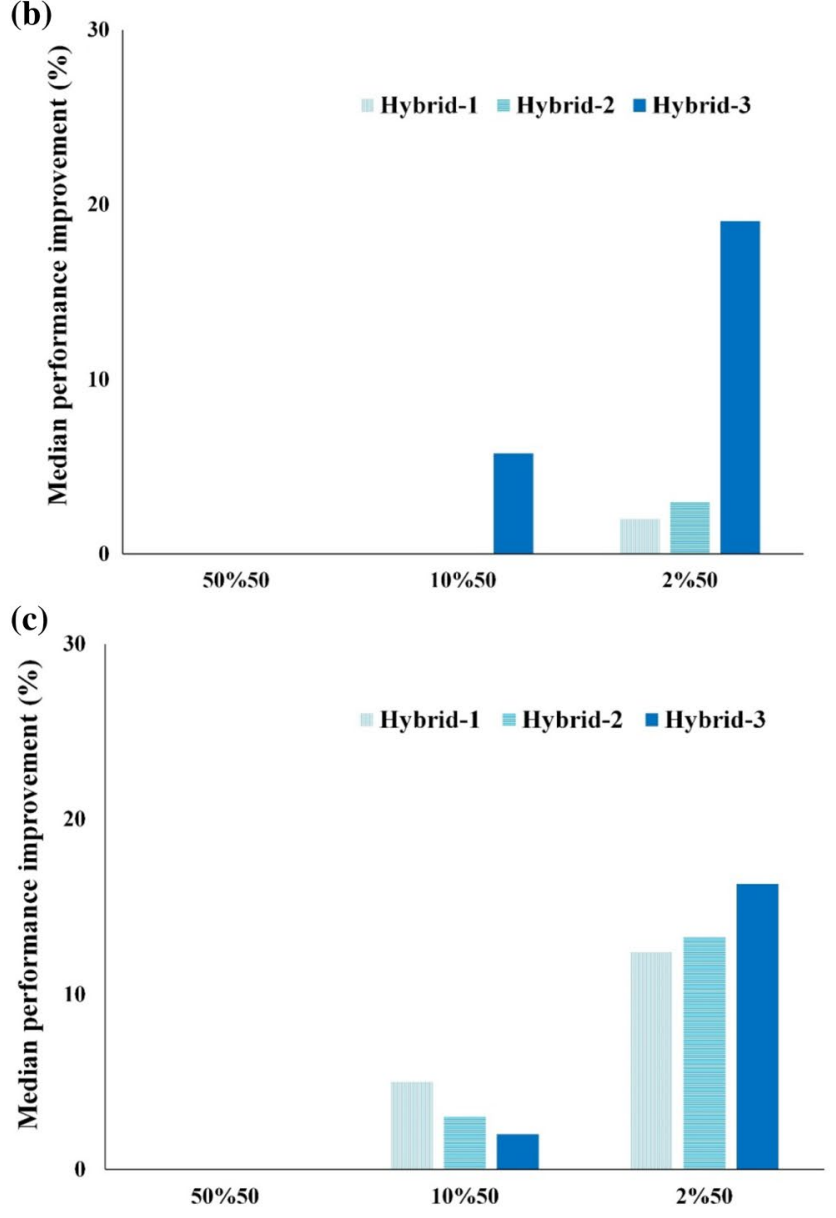

fixing and retrofitting the damaged structures after earthquakes (Ruiz-Garcia and Miranda 2010). Furthermore, residual displacements might have a significant impact on earthquake-induced economic losses since structures may be demolished due to extreme residual deformations even though they did not have moderate-to-severe damage. Therefore, estimation of relevant seismic demands associated with residual displacements under various earthquake hazard levels is required in a contemporary performance-based

characterizing the technical and economical possibility of 
seismic assessment procedure for the assessment of available structures.

The median performance advancement of hybrid BRBFs in comparison with the conventional frames regarding the residual roof displacement can be seen in Fig. 10. The residual roof displacement reduced as much as $20 \%$ for the 5- and 8 -story frames, by increasing the seismic intensities up to the collapse level. However, for 12-story models, the residual displacement decreased as much as $17 \%$, when the hybrid frame is considered. Hence, the advantage of hybridity is undeniable in residual roof displacement compared to IDR demand, and the most hybrid frame (the HBRB-3 type) carried out the best.

\section{IDA curves}

To evaluate the seismic performance and the collapse capacity of each building model, IDA was implemented using the 22 gradually scaled records in Table 4 in the case of the conventional and the hybrid BRB conditions. IDA curves are obtained by interpolating the resulting DM-IM discrete points in the IDA research. As explained before, IDA is strongly dependent on the record selected, so we have to resort to subjecting the structural model to an adequate number of seismic records. Such a study correspondingly produces sets of IDA curves which can be plotted on the same figure. Nonlinear response history analyses were performed from elasticity to building collapse level in small scaling increases to assess the behavior of the hybrid BRBFs versus conventional counterparts. Herein, some representative IDA curves are selected to study the general trend of seismic demands.

IDA was applied to calculate the collapse capacity of HBRB-3 models, and it is shown in Figs. 11 and 12. The damage measures including maximum IDR and residual roof displacement were computed for each of the 22 far-field ground motions. All curves demonstrate a different elastic linear region that ends when the first nonlinearity occurs. Regarding the other end of the curves, an ultimate softening part happens while DM is collected at increasingly higher rates by the structure. It actually represents the beginning of instability. Deformations rise without any limit when IM increases slightly. IM takes its maximum value and flattens out, but DM is continued to infinity. The structural system and the earthquake record are specified for each IDA curve; therefore, it is a deterministic process. However, an inherent randomness needs to be considered. Hence, a probabilistic characterization is required (Vamvatsikos and Cornell 2002). Thus, the single-record IDA curves are summed up to their median (50\% fractile). A central capacity curve is provided by the median values.

Dispersion in seismic response is an important outcome, but quantifying the median response is more important, e.g.,
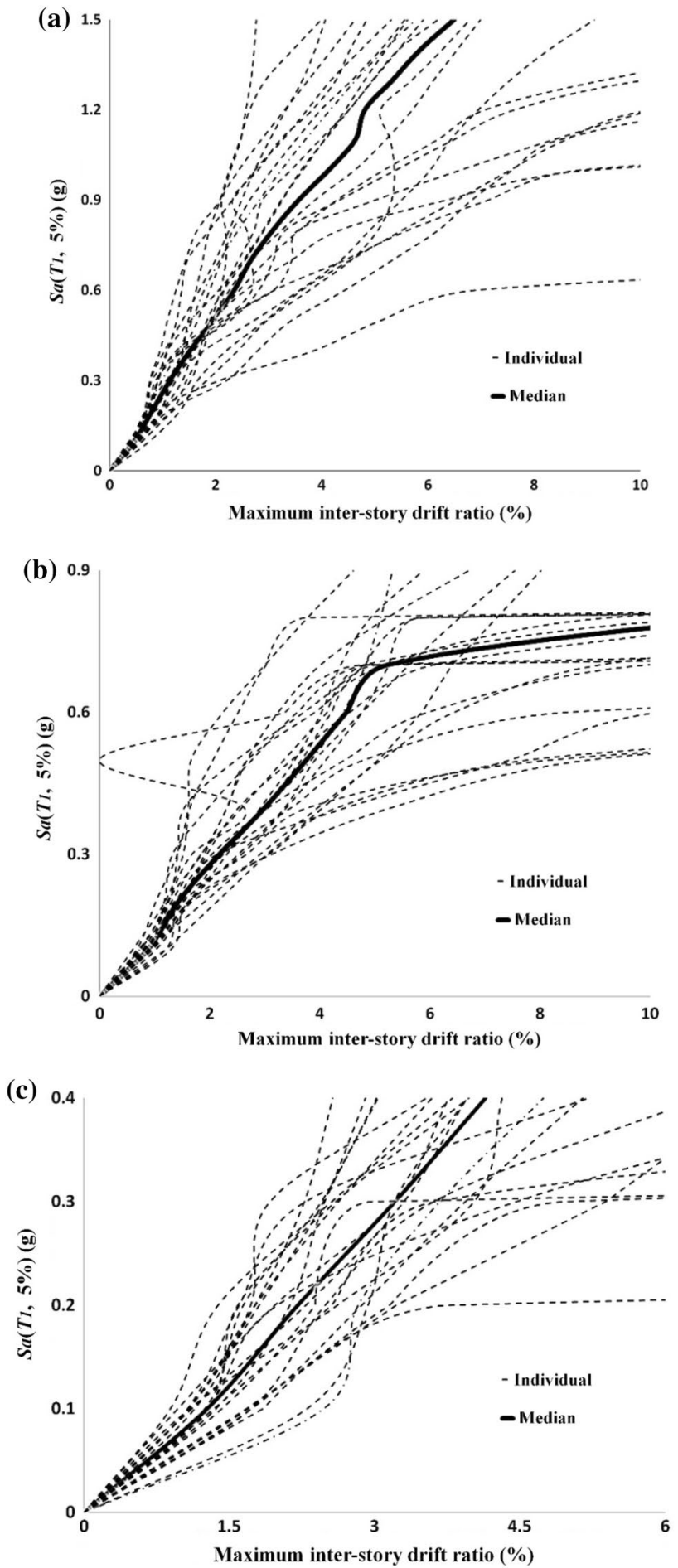

Fig. 11 The single-record IDA curves and the derived median IDA curves in terms of maximum inter-story drift ratio, corresponding to the hybrid-3: a 5-story frame, b 8-story frame and c 12-story frame

the median performance improvement. Figures 13 and 14 compare the median IDA curves for the conventional and hybrid BRBFs concerning the maximum IDR and residual roof displacement, respectively. A reliable performance 

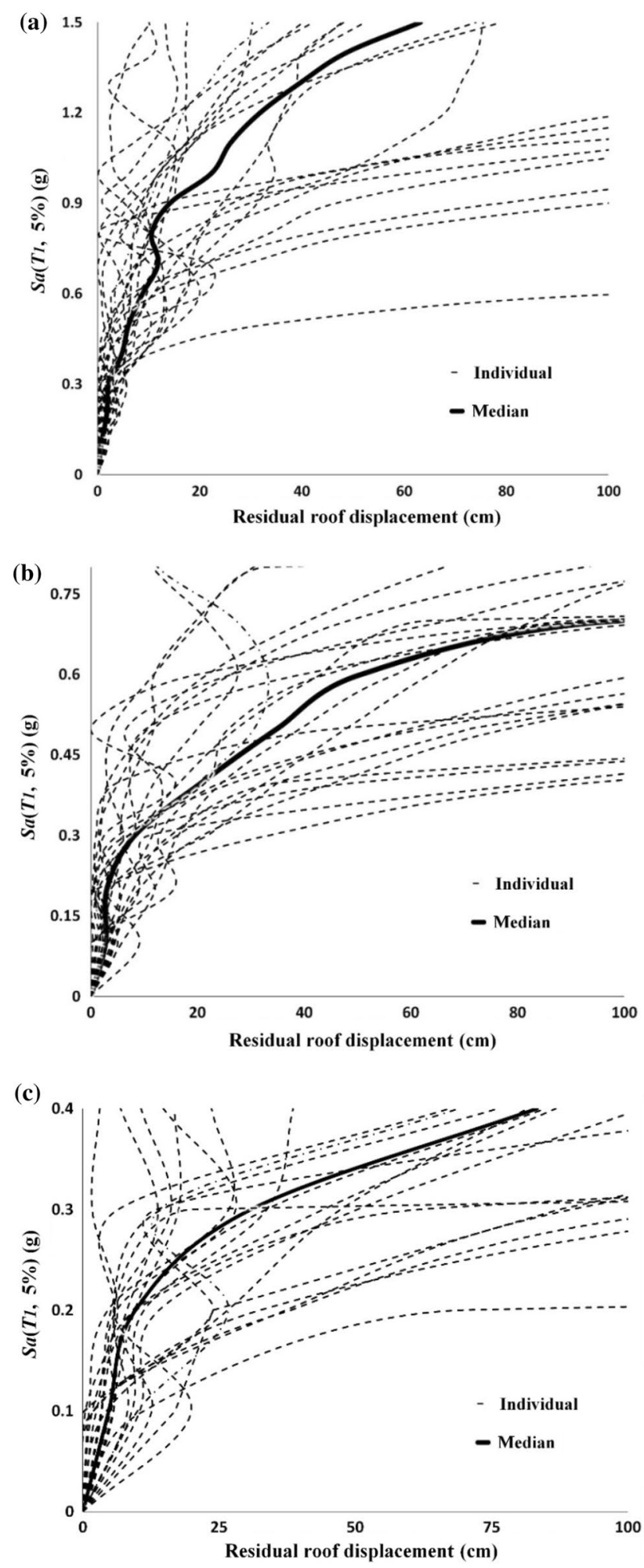

Fig. 12 The single-record IDA curves and the derived median IDA curves in terms of residual roof displacement, corresponding to the hybrid-3: a 5-story frame, b 8-story frame and c 12-story frame evaluation of the given building can be obtained by observing the influence of hybridity in the median IDA curves. As seen in Fig. 13a-c, the highest IDR does not change substantially with the hybrid frames. Furthermore, for each constant value of intensity measure, the maximum IDR increases with the structural height. In other words, different collapse capacity values are observed on the IDA curve for the structural models relying on their height. Also, the primary elastic stiffness of IDA curves is decreased, as the number of stories is increased. According to the obtained results in Fig. 13, the hybridity does not get a significant effect on reducing the IDR as the ground motion intensity and the number of stories in the model increases.

Figure $14 \mathrm{a}-\mathrm{c}$ illustrates the comparison of the median IDA curves of the hybrid and conventional BRBFs regarding the residual roof displacement. It can be observed that hybrid frames carried out better than the other one at all intensities up to the collapse level, and the most hybrid frame which has the highest percentage of LYP100 performed the best. As shown in Fig. 14, for each constant value of intensity measure, the residual roof displacement rises with the number of stories. In other words, plastic hinges are developed at low ground motion intensities as the structural height increases.

\section{Conclusions}

In this research, the seismic behaviors of diagonal-type hybrid BRBs were investigated and their performances were compared with the conventional counterparts using a selected number of low-to-mid-rise steel frames. Three analysis methods have been applied for seismic demands assessment of the 12 target steel braced frame buildings. The pushover analysis was performed to identify the load and the displacement relationship up to the ultimate state. The nonlinear response history and incremental dynamic analyses were carried out to observe dynamic behaviors and to compute the residual roof displacement and the inter-story drift. It was concluded that the hybridity has a significant role in altering seismic demands and improving energy dissipation capacity. Based on this study, the analysis results are summarized as follows:

- Response modification factor for HBRB-3, HBRB-2, HBRB-1, and conventional BRB models was suggested as $12.9,10.5,10.2$ and 9.8 on average, respectively. It is noted that the $R$ factor showed a significant decrease in frames as the number of stories increase. The increase in the $R$ value of the hybrid BRBFs indicates the system performance enhancement and consequently will result in a more economical structural design.

- Results show that hybrid frames yield sooner than typical frames. The early yielding and the delay in negative 

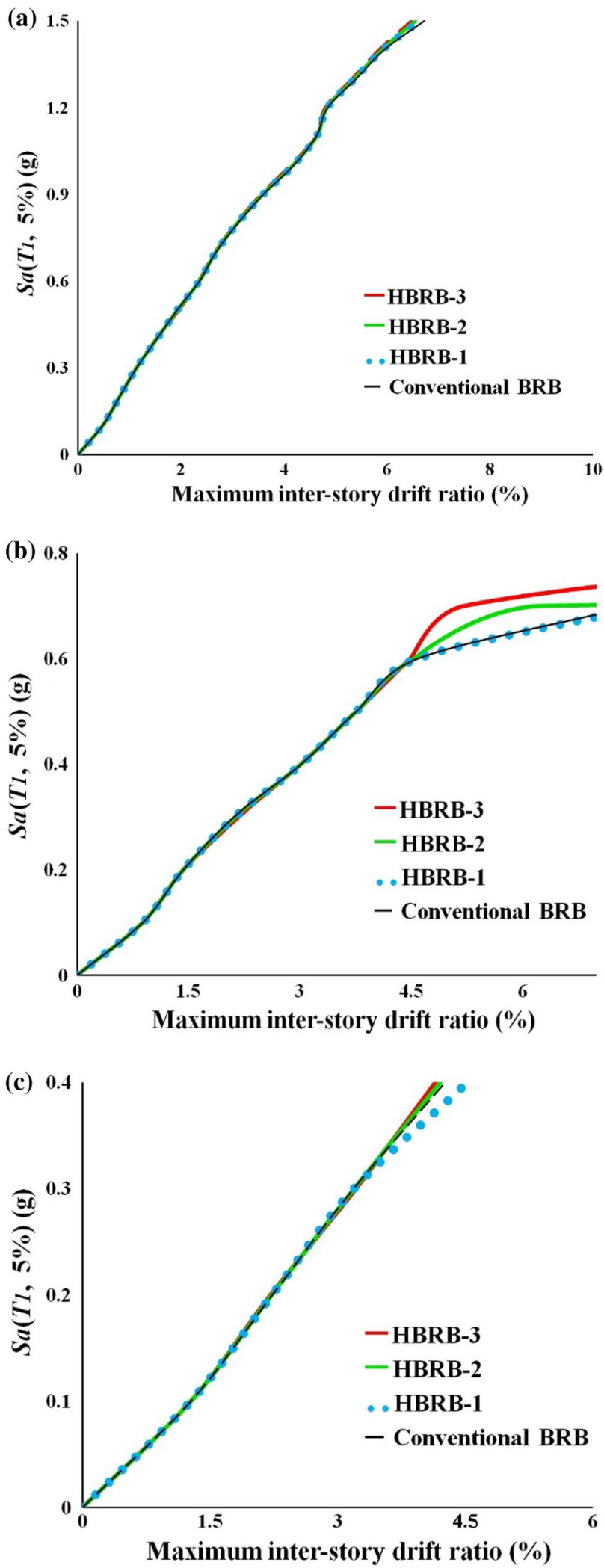

Fig. 13 The median IDA curves in terms of maximum inter-story drift ratio, comparing the conventional and hybrid BRB: a 5-story frame, $\mathbf{b} 8$-story frame and $\mathbf{c} 12$-story frame
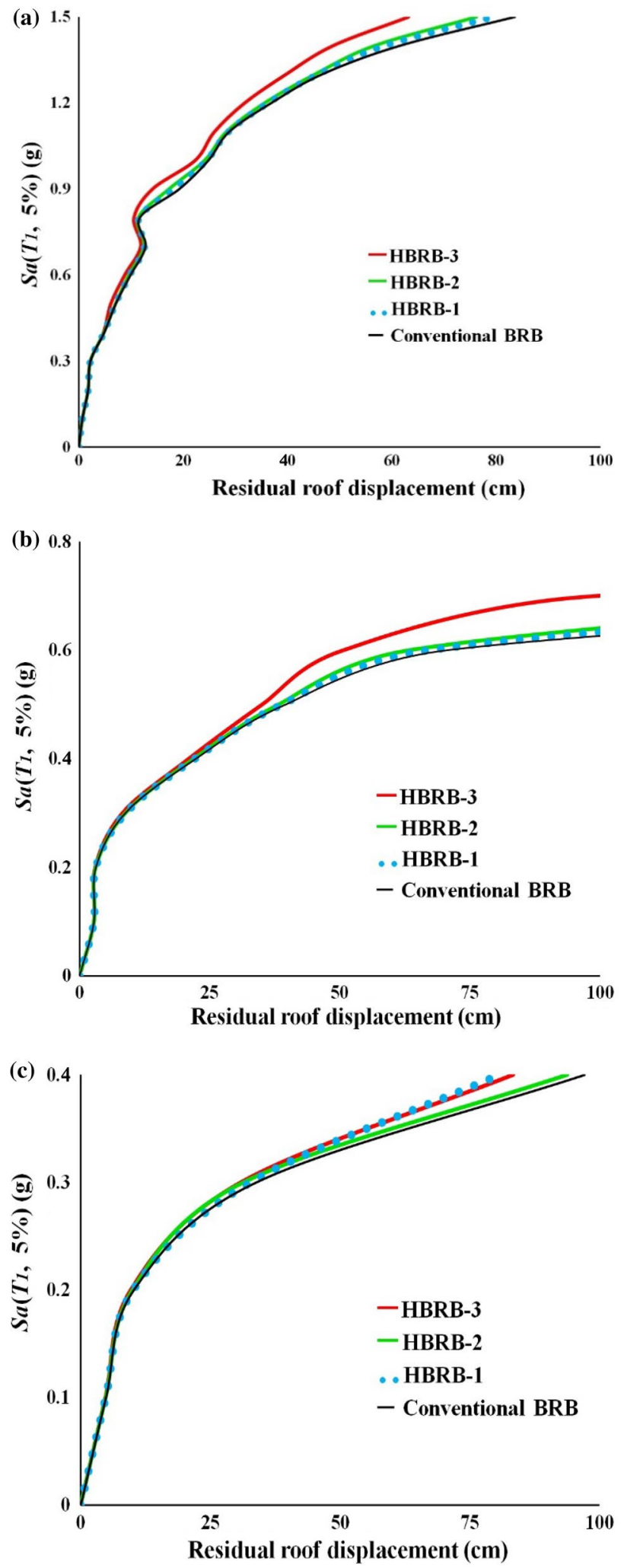

Fig. 14 The median IDA curves in terms of residual roof displacement, comparing the conventional and hybrid BRB: a 5-story frame, b 8-story frame and c 12-story frame 
post-yield stiffness drift ratio are becoming clear as the frames become more hybrid (from HBRB-1 to HBRB-3).

- The median residual roof displacements reduced as much as $20 \%$ for hybrid BRBFs, which is a promising outcome in terms of overall seismic performance. Thus, repairing the buildings applying hybrid BRBFs is cheaper as a result of lower residual displacements.

- The seismic performance of the low-rise hybrid BRBFs did not change substantially with respect to the maximum $I D R$. However, for the mid-rise frame (i.e., 12-story models), the median drift ratio decreased by up to $6 \%$ when hybridity was considered.

- According to the IDA curves, the HBRBs were observed to have considerable improvement over conventional systems regarding the studied damage measures as the ground motion intensities and the number of stories in the models increased. In other words, the use of HBRBs is more beneficial to the performance of tall buildings sitting in high-seismicity sites where $P-\Delta$ effects are more critical.

As mentioned, the results outlined in this paper will be helpful to quantify the beneficial effects of hybrid BRBs on the structural response so that the obtained information can provide guidance for developing the current seismic design codes. Yet, this study requires to be validated for further structures with a broader range of natural periods, various bracing configurations, an alternative combination of LYP and HPS materials, and the near-field ground motions. The performance of this ductile lateral resistance system can be developed through more researches.

Acknowledgements The authors would like to thank the anonymous reviewers for their constructive comments which helped to improve the manuscript.

Open Access This article is distributed under the terms of the Creative Commons Attribution 4.0 International License (http://creativeco mmons.org/licenses/by/4.0/), which permits unrestricted use, distribution, and reproduction in any medium, provided you give appropriate credit to the original author(s) and the source, provide a link to the Creative Commons license, and indicate if changes were made.

\section{References}

AISC (2010) Seismic provisions for structural steel buildings. ANSI/ AISC 341-10, American Institute of Steel Construction, Chicago

Alborzi Verki M, Tahghighi H (2019) Evaluation of seismic behavior of steel frames constrained with hybrid core bucklingrestrained braces. Amirkabir J Civ Eng. https://doi.org/10.22060 /CEEJ.2018.13837.5486 in press (in Persian)

Ariyaratana C, Fahnestock LA (2011) Evaluation of bucklingrestrained brace frame seismic performance considering reserve strength. Eng Struct 33:77-89
ASCE 7 (2010) Minimum design loads for buildings and other structures. ASCE/SEI 7-10, American Society of Civil Engineers/ Structural Engineering Institute, Reston

Asgarian B, Shokrgozar H (2009) BRBF response modification factor. J Constr Steel Res 65(2):290-298

ATC 3-06 (1978) Tentative provisions for the development of seismic regulations for buildings. Applied Technology Council, Redwood City

Atlayan O (2013) Hybrid steel frames. PhD thesis, Virginia Polytechnic Institute and State University, USA

Atlayan O, Charney FA (2014) Hybrid buckling-restrained braced frames. J Constr Steel Res 96:95-105

BHRC (2014) Iranian code of practice for seismic resistant design of buildings (Standard No. 2800). Building and Housing Research Center, Tehran

Bozorgnia Y, Bertero VV (2004) Earthquake engineering: form engineering seismology to performance based design. CRC Press LLC, Boca Raton

Broderick BM, Elghazouli AY, Goggins J (2008) Earthquake testing and response analysis of concentrically-braced sub-frames. J Constr Steel Res 64(9):997-1007

Bruneau M, Uang CM, Sabelli R (2011) Ductile design of steel structures, 2nd edn. McGraw-Hill Professional, NY

Chen CC, Chen SY, Liaw JJ (2001) Application of low yield strength steel on controlled plastification ductile concentrically braced frame. Can J Civ Eng 28(5):823-836

Chopra AK (2012) Dynamics of structures: theory and applications to earthquake engineering, 4th edn. Prentice Hall, NJ

Dong H, Du X, Han Q, Hao H, Bi K, Wang X (2017) Performance of an innovative self-centering buckling restrained brace for mitigating seismic responses of bridge structures with doublecolumn piers. Eng Struct 148:47-62

FEMA 356 (2000) Prestandard and commentary for seismic rehabilitation of buildings. Prepared by the Applied Technology Council for the Federal Emergency Management Agency, Washington DC

FEMA P695 (2009) Quantification of building seismic performance factors. Prepared by Applied Technology Council for the Federal Emergency Management Agency, Washington DC

Günther HP, Raoul J (2005) Use and application of high-performance steels for steel structures. International Association for Bridge and Structural Engineering, Zürich

Hoveidae N, Tremblay R, Rafezy B, Davaran A (2015) Numerical investigation of seismic behaviour of short-core all-steel buckling restrained braces. J Constr Steel Res 114:89-99

Jarrett JA, Judd JP, Charney FA (2015) Comparative evaluation of innovative and traditional seismic-resisting systems using the FEMA P-58 procedure. J Constr Steel Res 105:107-118

Kammula V, Erochko J, Kwon OS, Christopoulos C (2014) Application of hybrid-simulation to fragility assessment of the telescoping self-centering energy dissipative bracing system. Earthquake Eng Struct Dynam 43(6):811-830

Kiggins S, Uang CM (2006) Reducing residual drift of buckling-restrained braced frames as a dual system. Eng Struct 28(11):1525-1532

Kumar GR, Kumar SRS, Kalyanaraman V (2007) Behaviour of frames with non-buckling bracings under earthquake loading. J Constr Steel Res 63(2):254-262

López WA, Sabelli R (2004) Seismic design of buckling-restrained braced frames. Steel Tips, Structural Steel Educational Council (www.steeltips.org)

Mahmoudi M, Zaree M (2010) Evaluating response modification factors of concentrically braced steel frames. J Constr Steel Res 66:1196-1204

MHUD (2013a) Iranian national building code for structural loadings (part 6). Ministry of Housing and Urban Development, Tehran 
MHUD (2013b) Iranian national building code for steel structure design (part 10). Ministry of Housing and Urban Development, Tehran

Miller DJ, Fahnestock LA, Eatherton MR (2012) Development and experimental validation of a nickel-titanium shape memory alloy self-centering buckling-restrained brace. Eng Struct 40:288-298

Nakashima M, Iwai S, Iwata M, Takeuchi T, Konomi S, Akazawa T, Saburi K (1994) Energy dissipation behaviour of shear panels made of low yield steel. Earthquake Eng Struct Dynam 23(12):1299-1313

Newmark NM, Hall WJ (1982) Earthquake spectra and design. EERI Monograph Series EERI, Oakland

Nippon Steel (2009) Steel plates. Nippon Steel Corporation, Chiyoda

NIST (2010) Evaluation of the FEMA methodology for quantification of building seismic performance factors (NIST GCR 10-9178). Prepared by the NEHRP Consultants Joint Venture for the National Institute of Standards and Technology, Maryland

NIST (2012) Tentative framework for development of advanced seismic design criteria for new buildings (NIST GCR 12-91720). Prepared by the NEHRP Consultants Joint Venture for the National Institute of Standards and Technology, Maryland

OpenSees (2016) Open system for earthquake engineering simulation. Pacific Earthquake Engineering Research Center, University of California, Berkeley

PEER (2015) Strong motion database, http://peer.berkeley.edu, Pacific Earthquake Engineering Research Center, University of California, Berkeley

Qiu CX, Zhu S (2017) Performance-based seismic design of self-centering steel frames with SMA-based braces. Eng Struct 130:67-82

Ruiz-Garcia J, Miranda E (2010) Probabilistic estimation of residual drift demands for seismic assessment of multi-story framed buildings. Eng Struct 32:11-20

Sabelli R, Mahin S, Chang C (2003) Seismic demands on steel braced frame buildings with buckling-restrained braces. Eng Struct 25(5):655-666

Saeki E, Sugisawa M, Yamaguchi T, Wada A (1998) Mechanical properties of low yield point steels. J Mat Civ Eng 10(3):143-152

Shome N, Cornell CA (1999) Probabilistic seismic demand analysis of nonlinear structures. RMS Report-35: Department of Civil Engineering, Stanford University, Stanford
Sugisawa M, Nakamura H, Ichikawa Y, Hokari M, Saeki E, Hirabayashi R, Ueki M (1995) Development of earthquake-resistant, vibration control, and base isolation technology for building structures. Nippon Steel Tech Rep 66:37-46

Systani A, Asgarian B, Jalaeefar A (2016) Incremental dynamic analysis of concentrically braced frames (CBFs) under near field ground motions. Modares Civ Eng J 2:135-145 (in Persian)

Tahghighi H (2012) Simulation of strong ground motion using the stochastic method: application and validation for near-fault region. J Earthquake Eng 16:1230-1247

Tahghighi H, Rabiee M (2017) Influence of foundation flexibility on the seismic response of low to-mid-rise moment resisting frame buildings. Scientia Iranica 24(3):979-992

Tremblay R, Lacerte M, Christopoulos C (2008) Seismic response of multistory buildings with self-centering energy dissipative steel braces. J Struct Eng 134(1):108-120

Vamvatsikos D, Cornell CA (2002) Incremental dynamic analysis. Earthquake Eng Struct Dynam 31(3):491-514

Vamvatsikos D, Cornell CA (2005a) Developing efficient scalar and vector intensity measures for IDA capacity estimation by incorporating elastic spectral shape information. Earthquake Eng Struct Dynam 34:1573-1600

Vamvatsikos D, Cornell CA (2005) Seismic performance, capacity and rellability of structures as seen through incremental dynamic analysis. Department of Civil and Environmental Engineering, Stanford University, Report No.151

Vamvatsikos D, Fragiadakis M (2009) Incremental dynamic analysis for estimating seismic performance sensitivity and uncertainty. Earthquake Eng Struct Dynam 39(2):141-163

Wolf JP (1985) Dynamic soil-structure interaction. Prentice-Hall, New Jersey

Publisher's Note Springer Nature remains neutral with regard to jurisdictional claims in published maps and institutional affiliations. 